\title{
Educação sexual numa visão mais abrangente
}

\author{
Maria Alves de Toledos Bruns ${ }^{1}$ \\ Maria Virginia F. C. Grassi ${ }^{2}$ \\ Carlos França ${ }^{3}$
}

A sexualidade, entendida com o transcendente ao ato sexual, enquanto fonte de prazer ou desprazer e que se relaciona e se confunde com a história pessoal de cada ser humano, tem sua prática submetida a uma série de normas, valores e regras construídas ao longo do processo histórico-cultural de cada sociedade. A este conjunto de "intercondições, permissões, normas, valores e regras estabelecidas histórica e culturalmente, para controlar o exercício da sexualidade”, dá-se o nome de Repressão Sexual. (Chauí, 1984:9).

$\mathrm{O}$ homem, enquanto ser cultural, teve que reprimir seus instintos para que as civilizações pudessem existir, surgindo com isso a instauração das leis, normas, proibições. Estas proibições visavam ao controle, princi-

1. Doutora em Psicologia Educacional - Docente do Depto. de Psicologia e Educação da F. F.C.L. da USP -Campus de Ribeirão Preto.

2. Psicóloga-Mestrada do Curso de Pós-Graduação da Faculdade de Educação da Unicamp.

3. Doutor em Psicologia Educacional - Docente da Faculdade de Educação da Unicamp.

Recebido em 11.03.95 Aprovado em 15.03.95 
palmente, da atividade sexual e dos impulsos agressivos, para que a sociedade, assim como a conhecemos, se tornasse possível.

Ao que tudo indica, o homem, com medo de sua própria sexualidade e da força que o erotismo faz suscitar, procurando não conviver com sistemas autoritários, convenceu-se, por bem do sistema de trabalho produtivo, de que essa parte poderosa de sua personalidade deveria ser severamente controlada.

O trabalho, socialmente entendido enquanto força de produção, não somente torna-se um freio para o sexo, mas promove a dessexualização e deserotização do corpo. Segundo Marcuse (1969), a sexualidade é retirada de sua amplitude inicial, na qual faz parte de todas as ações humanas e passa a se restringir a momentos isolados, nas horas vagas. Além disso, é submetida a um controle, para que a procriação seja considerada fundamental, sendo reduzida à genitalidade. Até porque, seu descontrole poderia acarretar excesso populacional, ou mesmo a geração de filhos oriundos de relações irresponsáveis, acarretando maiores ônus para a sociedade na manutenção de crianças abandonadas pelos pais.

Esse processo de interdições, observado na história da humanidade, é registrado na literatura há muito tempo. Desde os tempos de Platão (séc. V a.C.), a alma, dicotomizada do corpo e superior a ele, deveria controlar os desejos a paixões suscitados por este. Era uma moral estética, na qual o belo apreciado era ter domínio de si mesmo.

Na Era Cristã (Séc. 1), a sociedade romana priorizava as práticas ascéticas com o objetivo de reproduzir virtudes morais. O prazer é controlado pela promoção de uma moral culposa e condenável, na qual ceder à sexualidade era perder a vida espiritual e afastar de si o paraíso e a civilização. Daí em diante, a Igreja, na Idade Média, apodera-se de qualquer tentativa de libertação consciente da sexualidade, reservando para si o direito da educação moral e espiritual dos homens no Ocidente.

A história da civilização se repete na educação de cada criança, onde se espera que, satisfatorialnente, ela vá se adequando às normas e leis sociais. Desde o primeiro momento de vida, o homem está inserido num contexto histórico, sendo que as próprias relações com o recém-nascido seguem um padrão que cada sociedade estabeleceu com o correto.

Para a organização social, aliás, habitualmente, a família é uma miniatura da sociedade. Segunda Bernardi (1985:25) "a família tende a imprimir na personalidade dos subordinados uma determinada estrutura psíquica, aprovada pela sociedade, e para isto vale-se de meios sugeridos pela própria sociedade". Em sua versão tradicional, a família desenvolve as funções de impor a própria autoridade, controlar a sexualidade dos filhos e de se apresentar como o modelo ideal de comportamento sexual. A identidade sexual e social de cada um de nós é construida, portanto, segundo este contexto no qual estamos inseridos. 
Essa visão de mundo que recebemos dos pais através de seus sistemas de valores, para Lane (1981) só irá ser confrontada no processo de socialização secundária, através da escolarização e profissionalização. Esse questionamento acontece principalmente na adolescência, época em que o jovem contesta os valores, crenças e normas. Não por ser a adolescência uma fase natural de contestação, como muitos estudiosos pretendem, mas porque através de outros laços afetivos, do desenvolvimento do pensamento lógico e de experiências sociais diferenciadas, o jovem se depara com outras alternativas, com outras visões de mundo, que o levam a questionar aquela que lhe foi apresentada como sendo a única possível.

É na escola, também, que o jovem entra em contato com outros valores e significados. Daí a importância de falarmos da sexualidade nas escolas, visto que é através dos valores confrontados que o homem elaborará sua própria conduta. A relevância está em discutir a educação sexual com os jovens como transmissão da realidade sentida por eles. E isto é importante porque a família, esquivando-se dos assuntos e vivências sexuais dos jovens, acaba por não lhes oferecer uma orientação sexual que realmente os auxilie em suas dúvidas e/ou dificuldades, delegando para a escola tarefas primordialmente suas.

Para Bernardi (1985), na família descomprometida com suas tais funções, o prazer da relação interpessoal é substituído pelos falsos prazeres do consumismo, a transposição afetiva e a emoção cedem o lugar à segurança de estabilidade econômica e social, a excitação se exaure numa monotomia sem esperança, a aventura transforma-se em odiosa rotina, a criatividade e a invenção naufragam na mecanização do comércio conjugal, o dar-se generosamente, torna-se possuir ciumentamente, a fidelidade recíprova é suplantada pelo contrato matrimonial. Nestes moldes, a família, no que toca à sexualidade, tem muito pouco para ensinar.

Em relação à escola, portanto, restar-nos-ia a esperança de oferecer aos jovens uma realidade diferente daquela que a família descomprometida lhe mostraria. Contudo, tal como a família, a escola, nos moldes tradicionais que a conhecemos, é uma instituição que tende a conservar a si própria e a reproduzir o descomprometimento da família. Mesmo porque se pensarmos em quem constitui a escola, saberemos que são seres humanos oriundos do contexto anteriormente exposto e, portamto, passíveis dos mesmos vieses a respeito da sexualidade.

O que temos, pois, é mais uma instituição que se alinha ao sistema social a às suas regras, no mais das vezes, inadequadas ao desenvolvimento de uma sexualidade sadia. O que fazer então? Será que o que nos resta é fechar os olhos à consciência do que já nos ofuscou a visão? Como abordar a sexualidade adequada se esta estiver ausente no próprio educador? 
Entender de sexualidade, sem antes compreender como a mesma se processo ou, em outras palavras, como a vivenciamos em nós próprios, fica muito difícil. É difícil entendê-la, mas muito mais é oferecer, enquanto educador, algo adequado aos outros, no caso, os alunos.

A sexualidade, como um todo, é a forma pela qual realizamos a existência do nosso corpo, sendo este o modo pelo qual entramos em contato com o mundo e que nos percebemos como sendo. Não temos outro meio de conhecer o corpo humano senão vivendo-o.

Nosso corpo simboliza a nossa existência porque a realiza e é sua atualidade. É por isto que quando falamos de sexualidade, remetemo-nos ao corpo a mesmo que se refira às descrições enfadonhas de órgãos e seus funcionamento, não podemos subtrair ao corpo a atividade que manifesta a sua dinâmica, portanto, o que sente, deseja e busca satisfazer. "A sexualidade é parte integrante do nosso self total. Ela não é apenas expressão do corpo biológico, não é apenas resultado do funcionamento glandular. Ela é a expressão do ser que deseja, que acolhe, que ama, que se comunica com o mundo e com o outro. Ela é uma "linguagem" que será tanto mais humana quanto mais pessoal for" (Aranha, M. L. H. e Martins, M. H. P, 1987:348).

Desta forma, o que é tido em algumas escolas como "educação sexual" é apenas uma informação que, às vezes, tende a ser impessoal e enfadonha, não atingindo o âmago da sexualidade humana, mas apenas dando continuidade às assexuadas regras e normas vigentes. Isto para não falarmos da quase total ausência desta ineficiente informação. Trata-se de uma educação adulta, madura e fisiológica, concentrada nos órgãos sexuais, eliminando a sexualidade humana de todo o corpo, que é definida como perverse a imatura. O corpo é relegado a uma zone, a uma região e, portanto, toda a imagem corporal que leva à própria identidade pessoa fica fragmentada, suja, incomplete. Essa educação, ao deixar de lado o mistério do prazer, corre o risco de colocar o homem no mesmo plano "dos galos e das violetas".

Pare Merleau-Ponty (1971), o sexual não é o genital, a vide sexual não é um simples efeito dos processos cujo centro são os órgão genitais, a libido não é só um instinto, isto é, uma atividade orientada para fins determinados. Ela é o poder geral que tem o sujeito de aderir a diferentes meios e fixer-se por diferentes experiências, de adquirir estruturas de conduta, ela é o que fez com que o homem tenha uma história. Se a história sexual de um homem dá a chave de sue vide, é porque na sexualidade do homem se projeta a sua maneira de ser com relação ao mundo, isto é, com relação ao tempo e aos outros homens.

Neste sentido, ao dirigirmos o olhar nessa direção, percebemos que somos "lançados" ao mundo sob o prisma moralístico e repressor. Embora assistindo a muitas modificações nestas últimas décadas, a sexualidade continua ainda muito velada, não obstante tenha sempre estado presente nas relações entre os seres humanos, mesmo que de um modo não consciente. 
Sob a perspectiva de que, junto com as mudanças de valores e crenças na sociedade, ocorrem mudanças de atitudes e modificações no modo de sentir e ser, Bruns e Grassi (1991) realizaram um estudo com jovens de classe média, de 13 a 18 anos, intencionando conhecer o nível de diálogo sobre o sexo com os pais, e compreender as concepções próprias dos jovens em relação à virgindade, heterossexual idade e homossexualidade.

Os resultados evidenciaram que a instrução sexual é mais difundida e aberta aos rapazes, e mais concentrada na família, e mais reservada para as garotas. Os rapazes vêem com mais preconceito do que as garotas, o corpo de alguém do mesmo sexo. Em relação à atração pelo sexo oposto, este estudo mostrou que as garotas são atraídas, em primeiro lugar, por características de personalidade, a atração física ocorre após um grau maior de envolvimento com o parceiro. Para os rapazes, apesar da valorização do corpo da mulher, a busca é por uma mulher mais integrada, que além de possuir um corpo belo, seja carinhosa, sensual e autêntica. Percebe-se, também, nesse estudo, a reformulação dos antigos valores conservadores em relação à virgindade e à masturbação.

Assim, a busca de identidade, característica dessa fase, leva os jovens a uma redefinição, para ambos os sexos, de valores e conceitos aprendidos. Desse modo, esse estudo contribuiu para a compreensão de que, atualmente, rapazes e moças estão tentando superar, reformular conceitos, normas e preconceitos legados por gerações anteriores, em que as "marcas" das proibições e repressões eram "enfatizadas" e "cobradas" como normas de condutas e comportamentais.

Hoje estão se lançando em buca de uma realização sexual mais aberta, satisfatória, menos desigual, e, de certa forma, "permitida" pelo próprio momento histórico, e porque não dizer, mais autêntica? Fechar os olhos a estas mudanças, fazer de conta que os jovens são assexualizados, parece-nos que tem sido a atitude de muitos pais e da escola, visto o numero assustador de mais e pais adolescentes. A gravidez precoce é a evidência concreta do desejo, do tão velado mistério do prazer. E tem causando pânico e desespero para várias famílias, levando mães e pais jovens a experienciarem um modo de viver altamente conflituoso e desgastante.

Quase sempre é a mãe jovem, a garota, a única responsável por um momento de prazer vivido a dois. Cabe-lhe solucionar o "problema" via aborto e/ou assumindo sozinha o fruto do desejo. Para poucas famílias que se preocupam em oferecer informação sexual para os filhos - fica a surpresa, a perplexidade - e se perguntam: "por que minha filha ficou grávida? Eu lhe oferecia livros e respondia a todas as suas questões sobre sexo".

Responder questões sobre sexo, parece-nos que não tem sido suficiente. Informar é preciso, para o vivenciar a sexualidade no seio familiar é ir além das informações, mesmo porque as informações, assim como as palavras e os signos. não dão conta do vivido. Há um excedente no senti- 
do proveniente da experiência do ir-à-coisa-mesma" (Ricoeur, 1979:16). Assim, quando o jovem vai em busca de si mesmo para encontrar no outro com sua identidade sexual, o que leva consigo, mais que informações, são as impressões das vivências de seus relacionamentos primários no meio familiar. É o excedente não dito mas tão sutilmente captado por nossas "inocentes" crianças.

Com falta de informação e formação sexual, o jovem vai se encontrar com o mistério do prazer, com o desejo não elaborado, não discutido, não refletido, não trabalhado nem na família e nem na escola. E, no mais das vezes, permitir-se o novo no extraordinário momento de estar com o outro, sem contudo saber conduzir suas próprias emoções, seus limites e até definições do que busca realmente, perdendo-se em conflitos e imprevidências.

Em pesquisa realizada por Bruns e Grassi (1993), as jovens se sentem inseguras por não terem uma definição do que realmente é "namorar", "ficar", "transar", por terem modificado Padrões, mas ainda não colocarem em substituição algo que lhes dê segurança, certeza, ou por não contarem, também, com informações esclarecedores que as auxiliariam em sua formação como mulher, seguras de uma identidade própria, sexuada, apropriada para enfrentar os desafios e inconstâncias de um novo tempo vivido.

Enquanto, pela vida afora, a busca do outro continua, levando as pessoas a se procurarem, a se precisarem mutuamente para se encontar, a sexualidade continua moralmente silenciada, velada no vulcão das emoções de cada um de nós. Mantê-la inerte já nos causou anos de escravidão mental, danos físicos, "couraças corporais" a alienapão de nós mesmos. E o quanto a educação de todos nós não será mais bela e real, quando formos inteiros, repensando nossa sexualidade em diálogo aberto e franco com nós mesmos e com os outros, para sermos mais humanos enquanto educadores...

\section{REFERÊNCIAS BIBLIOGRÁFICAS}

1. ARANHA, M. L. A. e MARTINS, M. H. P.: Filosofando- Introdução à Filosofia, São Paulo, Moderna, 1987.

2. BERNARDI, M.: A Deseducação Sexual, São Paulo, Summus, 1985.

3. MARIA, A. T. B. e GRASSI, M. V. F. C. Sexualidade: discurso do corpo: um estudo de caso, in Revista Brasileira de Sexualidade Humana, vol. 11, 1991, pp. 79-92.

4. BRUNS, M. A. T. e GRASSI, M. V. F. C.: Mulher e Sexualidade: o desejo de continuidade, in Revista Brasileira de Sexualidade Humana, vol. IV, 1993, pp. 88-103.

5. CHAUI, M.: Repressão Sexual: essa nossa (des)conhecida. São Paulo, Brasiliense, 1985. 
6. LANE, S. T. M.: O que é Psicologia Social, São Paulo, Brasiliense, 1981.

7. MARCUSE, H.L: Eros e Civilização, $4^{\mathrm{a}}$ ed. Rio de Janeiro. Zahar, 1969.

8. MERLEAU-PONTY, M.: Fenomenologia da Percepção. Rio de Janeiro, Freitas Bastos, 1971.

9. RICOEUR. P.: O Conflito das Interpretações, Rio de Janeiro, IBRAP, 1979. 